Prevalence of dental anxiety and associations with oral health, psychological distress, avoidance and anticipated pain in adolescence: A cross-sectional study based on the Tromsø study, Fit Futures.

Hege Nermo $^{\mathrm{a}, \mathrm{c} *}$, Tiril Willumsen ${ }^{\mathrm{b}}$ and Jan-Are K. Johnsen ${ }^{\mathrm{c}}$

${ }^{a}$ The Public Dental Health Service Competence Center of Northern Norway, Tromsø, Norway; ${ }^{b}$ Department of Pediatric Dentistry and Behavioural Science, Faculty of Dentistry, University of Oslo, Oslo, Norway ; ${ }^{c}$ Department of Clinical Dentistry, Faculty of Health Sciences, UiT The Arctic University of Norway, Tromsø, Norway

*Correspondence to: Hege Nermo, Department of Clinical Dentistry, Faculty of Health Sciences, UiT The Arctic University of Norway, 9037 Tromsø, Norway. Email: hege.nermo@uit.no 


\title{
Prevalence of dental anxiety and associations with oral health, psychological distress, avoidance and anticipated pain in adolescence: A cross-sectional study based on the Tromsø study, Fit Futures.
}

\begin{abstract}
Objective. To describe the prevalence of dental anxiety (DA) among adolescents in Tromsø and Balsfjord region in northern Norway and present a multivariate logistic regression model to predict high dental anxiety scores among these adolescents.
\end{abstract}

Material and Methods. We used self-report questionnaires and clinical dental examination data from adolescents registered in upper secondary school (15-18 years of age) in this region ( $\mathrm{n}=986$ ). Logistic regression was used to estimate odds ratios and their 95\% confidence intervals (CI) when using Corah’s Dental Anxiety Score (DAS) as a dichotomous dependent variable.

Results. Twelve percent of the respondents reported a DAS score $\geq 13$, indicating high dental anxiety. The strongest predictors for reporting high DA were anticipated pain at the dentist, "external control belief”, avoidance, low social motivation on oral health behavior and sex.

In this population, dental caries (DMFS), symptoms of psychological distress (HSCL-10), and self-motivation concerning oral health behavior did not differ significantly between those reporting high $\mathrm{DA}(\mathrm{DAS} \geq 13)$ and those that reported low DA $(\mathrm{DAS} \leq 12)$.

Conclusion. Severe dental anxiety in adolescence is a dental public health challenge and this study shows that dental anxiety is a hindrance to seeking dental treatment irrespective of dental status. Dental anxiety should have a higher focus on preventive oral health strategies and have a higher priority in public dentistry to avoid this problem to escalate into adulthood. 
Keywords: dental fear, dental phobia, oral health, adolescents, public health dentistry 


\section{Introduction}

Dental anxiety is a common problem experienced in dental practice. The reported prevalence of dental anxiety among children and adolescents are reported ranging from 5.7\% to $19.5 \%(1,2)$. Seligman et al (3) proposed a cognitive-behavioral model to explain the development and maintenance of dental anxiety in youth based on a review of previous findings. The etiology of dental anxiety from this review emphasize classical conditioning as key. This review also concludes that we need a better understanding regarding both physical and psychological consequences of dental anxiety among youth, including what core processes that come into play and more accurate prevalence data (2). Arguably, the majority of evidence explaining etiology, maintenance, and consequences of dental anxiety is based on studies of adults.

Adolescence is a transitional stage between childhood and adult, a turbulent time in life consisting of considerable development and change within biological, emotional and social systems (4). Adolescents are increasingly independent and during this period, they have to establish their own health behaviors and attitudes (5). As dental fear is associated with avoidance of treatment (6), unfavorable oral health behavior or attitudes that develop in this stage can be argued to lead to more oral disease, both in the short and long term. With regards to dental health behavior, it is a challenge that the onset of dental anxiety appears to be prominent in childhood and adolescence. A retrospective study by Locker et al. (7) found that half of the respondents reported that their dental anxiety started in childhood years, while 22\% reported onset of dental anxiety in adolescence. Thus, it is reasonable to assume that avoidance of dental treatment due to fear is established in this period of life, and exploring dental anxiety in this age group in population studies should be of special interest.

Oral health is a multifaceted concept. Oral health, according to the World Dental Federation, is a fundamental component of health and physical and mental well-being (8). 
Several constituents of oral health have been associated with dental anxiety. Dental anxiety has been linked to more caries experience in adults (9) and even as a predictive variable for developing caries in adolescents (10). Poor dental status among anxious patients is often explained by avoidant behavior (11). Avoidant behavior can result in inadequate dental treatment, which among adults could lead to deteriorating oral health (12-14), and adults suffering from dental anxiety indicate poorer oral hygiene practices than non-anxious patients (15). Avoidance or enduring dental treatment with intense anxiety is one of the diagnostic criteria for specific phobia according to the American Psychiatric Association (16). The relationship between dental health status, anxiety, and avoidance of treatment is probably complex, involving a wide range of factors from socio-economical to psychosocial aspects $(11,17,18)$, but avoidant behavior can eventually lead to less functional teeth among adults (13). Impaired dental status is a great source of shame among patients with dental anxiety. Embarrassment and feelings of shame or guilt related to social interactions such as eating, smiling, and talking can negatively impact social interaction, and lead to a decline in quality of life $(17,18)$.

Adult patients with high levels of dental anxiety report problems in many aspects of life, including psychological and social disability and reduced quality of life $(19,20)$. Studies have found associations between dental anxiety and signs of depression and anxiety in both adults (21) and adolescents (22). The direction of the association between these measures is unknown. Reporting dental fear combined with general fears are associated with higher psychological distress and more psychosocial consequences (23). However, it is not known what role general psychological distress plays in adolescence in relation to dental anxiety. Potentially, young individuals with heightened psychological distress could be more vulnerable to developing dental anxiety, perhaps due to being more predisposed to mental problems. However, adolescence is also a period of change and potential turmoil, 
where psychological distress could be an expression of natural processes rather than mental illness or psychological vulnerability.

Pain is a complex and subjective human experience and pain reported in the dental setting is influenced by a number of different factors (24). Dental treatments requiring injections or considered invasive are more strongly associated with reports of pain, as are feelings of lack of control and dental anxiety (24). Dental anxiety is predictive of reporting pain during dental treatment (25). Studies have shown that fearful individuals expect more pain and need additional painless treatment sessions to adjust their expectancy, compared with non-fearful adults $(26,27)$. Pain is regarded to be a strong important part of the conditioning process leading to dental anxiety (e.g., for children), but it is not clear if pain plays an equally important part of dental anxiety development for all age groups. Interestingly, studies have found that the experience of pain during dental procedures might differ between age groups and that these differences are not only due to procedural differences. For instance, adolescents (14-17 years of age) have been found to find orthodontic treatment more painful than children and adults (28), and adolescent girls (1417 years of age) appear to find orthodontic treatment more painful than boys at the same age and younger adolescents (11-14 years of age; (29). Thus, there seems to be some evidence that adolescents might be more prone to experience dental treatment as painful compared to other age groups, and that this might impact their expectations of future treatment sessions (anticipation of pain) and consequently the development of dental anxiety.

When considering differences between sexes, most studies on dental anxiety among children and adolescents have reported that females are more dentally anxious than males (1). The reasons for these sex differences have been suggested to be an interplay of biological and sociocultural factors, which might be especially relevant in adolescence as this is a developmental stage particularly concerned with gender roles (30). 
Fit Future provides an extensive mapping of oral and general health in adolescence in the north of Norway. (Available from http://www.tromsostudy.com)

The aims of this study were to describe the prevalence of dental anxiety among adolescents in the Tromsø and Balsfjord region of northern Norway and explore how etiological concepts of importance to dental anxiety contribute in predicting high dental anxiety scores in an adolescent population (see Figure 1). We also hypothesized that pain plays an important role in dental anxiety among adolescents, and specifically that anticipation of pain would be significantly higher in adolescents with high dental anxiety compared to those with low dental anxiety.

\section{Method}

\section{Study population and design: Fit Futures}

In 2010-2011, all first-year upper-secondary school students in the two neighboring municipalities Tromsø and Balsfjord in northern Norway were invited to participate in the cross-sectional study Fit Futures 1. Fit Future is an expansion of the Tromsø study [The Tromsø Study. Available from http://www.tromsostudy.com], and provides an extensive mapping of oral and general health in adolescence in the north of Norway. The study focuses on general health, including a wide range of clinical examinations and collection of biological samples, including a dental examination. Out of 1,117 invited, 1,038 adolescents (508 females and 530 males) attended the study, providing an attendance rate of $92.9 \%$. All participants gave written consent and participants younger than 16 years had written permission from their guardian. We excluded participants over 18 years old due to our age range of interest and ended up with 986 eligible for final analyses (Figure 2).

The Regional Committee of Medical and Health Research Ethics (reference number 2014/1093/REK Nord) approved the study in September 2014.

\section{Measurements}


Dental anxiety was measured by Corah’s Dental Anxiety Scale (DAS;31). The scale yields a score of 5 to 20, where high scores indicate greater anxiety. In accordance with similar studies, we classified individuals with DAS scores of 13 or more as dentally anxious $(10,32,33)$. The internal consistency and test-retest reliability of the scale is high (34). The Cronbach's alpha coefficient is .91 in this study.

We used several different measurements in order to describe the multifaceted concept “oral health”. This included: oral status as indicated by DMFS, motivation, knowledge, and attitudes regarding tooth brushing. The clinical examination done in this study registered caries experience (according to DMF), but also the quality of fillings, erosions etc. We even had a self-reported oral health measure from the participants. We performed a correlation analysis on all these measures (not reported) and due to the high correlations and widespread use of the Decayed, Missing, Filled index (DMF), chose this as our variable for oral status. It has been used for more than 70 years and is well established as the key measure of caries experience in dental epidemiology (35). The maximum value for DMFS comes to 128 for 28 teeth (36). Description of the details concerning the clinical oral examination can be found in a previous article on this dataset describing the caries prevalence (37). In the oral health questionnaire of the study, there were 23 questionnaire items concerning oral health knowledge and behavior. Participants responded to these items by using the four-point Likert-scale reply, ranging from “completely agree” (=1) to “completely disagree” (=4). A similar set of items have been used previously by Tolvanen et al. (38, 39), but the current study included 5 additional items regarding knowledge about tooth brushing and attitudes regarding caries (see item 1-5, Table 1). Also, a comparison of the exact wording of translated items used by Tolvanen et al. (38) to those used in the current study showed differences that made it unclear whether items have the same meaning in these studies. These differences could be due to differences in translating to English from Finnish versus Norwegian language. To investigate these issues, we performed an 
explorative principal components factor analysis with varimax rotation. The initial factor solution indicated six components with Eigenvalues above 1.0, explaining between 27.7 and 4.5 percent of the variance. However, the six-factor solution was conceptually not meaningful, and after a visual inspection of the scree plot, it was decided to proceed with a two-component factor solution explaining about 43 percent of the variance. The first component contained items related to knowledge and attitudes about tooth brushing and we identified these questions as self-motivation concerning oral health knowledge and behavior. The second component contained items related to the embarrassment of having caries and the importance of tooth brushing for recognition from parents and friends. These items were identified as indicating social motivation related to oral health and behavior. The translated questionnaire items can be viewed in Table 1 alongside the rotated factor solution. Two subscales were constructed based on the factor solution, called SelfMotivation and Social Motivation, and these were tested for reliability. The Cronbach's alpha coefficient is .88 for the Self-Motivation subscale and .85 for the Social Motivation subscale. Sum scores of these subscales would be used for further analyses and we dichotomized the scales into high or low scores by using the median.

The statement "Whatever I do, it doesn't help to prevent caries” did not fit any of the two components, loading less than .3 on either component. We decided to use this statement as a single item. We refer to this item as "control belief”, describing expectations about whether one can influence caries experience or not, for instance, if preventing caries is predominantly influenced by one's own behavior or predominantly dependent on chance or luck.

[Table 1 near here] 
Anticipated pain reflects the students' reports on how painful they judged an average dental session to be. They were to indicate pain on a scale from zero, (no pain) to ten (worst conceivable pain).

Participants indicated avoidance due to fear by responding "yes" or "no" to the question: "Have you ever missed a dental appointment due to fear?” We refer to this variable as "avoidance" in the text and analysis.

Psychological distress was measured using the Hopkins Symptoms Check List (HSCL - 10). HSCL-10 is a short version of the more extensive HSCL-90 and HSCL-25 and is validated and recognized for use in epidemiological studies and in clinical work among youth measuring symptoms of depression and anxiety (40). HSCL-10 has a good internal consistency, with a reported Cronbach's alpha coefficient of .87 (40). The Cronbach's alpha coefficient for the current dataset is .874. An average HSCL-10 score over 1.85 was set as an indicator for symptoms of anxiety and/or depression as recommended by former research (41).

All analyses were performed using IBM Statistical Package for the Social Sciences (SPSS) Statistics version 24. We performed a correlation analysis, bivariate t-test and a multivariate logistic regression analysis with DAS score as a dependent variable. In the bivariate and multivariate analysis, we dichotomize DAS score, separating those with high DAS score $\leq 12$ from the ones with low scores $\geq 13$. Pairwise exclusion was used for missing data; hence, the number of observations varies in the respective analyses. We used median scores to dichotomize the self- and social motivation scores into groups with either high (above median) or low scores (below median).

\section{Results}

\section{Descriptive analysis}


Our total population consisted of 986 students, $51.6 \%$ males and $48.4 \%$ females in the age between 15 and 18. Twenty-five of the 986 included in the study did not undergo the dental examination. The majority of adolescents, 93.7\%, were born in Norway. Most of their biological parents were also born in Norway (91\%, n=974). Many of the adolescents did not know their parents' educational level (mother 26.2\% and father 29.2\%), but $36 \%$ of the parents had higher education (see Table 1).

[Table 2 near here]

The mean score of DAS was 8.0, with a standard deviation of 3.5 in this population. High dental anxiety scores, DAS score $\geq 13$, was reported by $11.6 \%$ of the adolescents. Severe dental anxiety (DAS $\geq 15$ ) was found for $5.7 \%$ in this population. Females reported more dental anxiety than males did, $15.9 \%$ of the females reported a DAS $\geq 13$ compared to $7.5 \%$ of the males (Table 2).

The mean DMFS score was $6.4(\mathrm{SD}=7.0)$. Sixteen percent of the adolescents had no caries lesions in need of conservatory therapy. Fifty percent had less or equal to three fillings in total (fillings due to any reason) and $17.8 \%$ had no experience with conservative therapy at all.

Considerable psychological distress was found in $19 \%$ of the adolescents when using 1.85 as a cut-off on the HSCL-10 scale.

[Table 3 near here]

\section{Correlation analysis}

As part of including variables of interest in our multivariate regression model and looking at covariance between the different measures, we performed a correlation analysis. We found that there was a strong positive correlation between sum DAS score and how 
painful the adolescent judged a normal dental session to be; Pearson's $r=.731, p<.01$. This indicates that dental anxiety explains about $50 \%$ of the variance in the respondents' scores on perceived pain in a normal dental session. When comparing this to dental health score, we found a small positive correlation between DAS score and DMFS score; Pearson's $r=$ $.261, \mathrm{p}<.01$; which indicates that dental anxiety explains only about $8 \%$ of the variance of the number of caries lesions.

[Table 4 near here]

\section{Bivariate analysis}

We expected that anticipated pain would be different between adolescents that reported high versus low dental anxiety. To evaluate the difference in mean anticipated pain score between adolescents with high and low dental anxiety scores, we used independent-samples t-test. There was a significant difference in anticipated pain scores between highly anxious individuals $(\mathrm{M}=7.18, \mathrm{SD}=2.33)$ and those with lower anxiety scores $(\mathrm{M}=2.47, \mathrm{SD}=2.29) ; \mathrm{t}(942)=-20.58, \mathrm{p}<.001$. The effect size was large (eta squared $=.309$ ) which shows that high dental anxiety scores explain $30.9 \%$ of the variance in anticipated pain at the dentist.

\section{Multivariate analysis}

In order to model the impact of the different concepts, we performed a direct logistic regression analysis with eight independent variables (Sex, DMFS, HSCL-10, Anticipated Pain, Avoidance, Control Belief, Self-Motivation and Social Motivation concerning oral health behavior) and DAS score as the dependent variable. Collinearity diagnostics showed high tolerance values for all variables $(>$.79) and VIF values $<1.259$. The full model containing all predictors was statistically significant; $\chi^{2}=(8, \mathrm{n}=822)=$ 288.88, $\mathrm{p}<$.001; which indicates that the model was able to distinguish between 
respondents who reported high dental anxiety and those that reported low dental anxiety. The model as a whole explained 57.4\% (Nagelkerke R-squared) of the variance in dental anxiety, and correctly classified $92.5 \%$ of the cases. As shown in Table 4 (logistic regression table) and Figure 4, five of the independent variables made a statistically significant contribution to the model (Sex, Control Belief, Anticipated Pain, Avoidance and Social Motivation concerning oral health and behavior). The strongest predictor of reporting high dental anxiety was agreeing with the statement: “Whatever I do, it doesn’t help to prevent caries”. Indicating that those feeling a lack of control over own caries disease were 4.6 times more likely to report high DAS. For every increase on the pain scale, the respondents were almost two times more likely to report high dental anxiety. The students that reported missing a dental session due to fear were 3.4 times more likely to report a

DAS score over 13. Females were twice as likely to report dental anxiety as males were. When it comes to external regulation or social motivation as we refer to it, we found that being motivated by recognition and embarrassment to maintain oral health gives a lower chance of being dentally anxious. Those with low social motivation scores were twice as likely to report high dental anxiety.

[Table 5 near here]

\section{Discussion}

This study found that approximately $11.6 \%$ of adolescents in the Tromsø-region of North Norway reported high levels of dental anxiety (DAS $\geq 13$ ). This agrees well with other comparable studies $(33,42)$. Fewer than ten percent $(7.5 \%)$ reported that they had missed a dental appointment due to fear. Levels of anticipated pain and reported avoidance due to fear differed significantly between the anxious and non-anxious adolescents, in contrast to caries experience. 
The predictive values of the different independent variables in our multivariate regression analysis support former evidence indicating that females are more prone to dental anxiety than males (43). Our data suggest that the interaction between dental anxiety and anticipated pain at the dentist among adults (24) are equally relevant in adolescence. We found support for the hypothesis that adolescents with high dental anxiety scores would report significantly higher levels of anticipated pain at the dentist than adolescents with lower dental anxiety scores. We are not sure if the registered "Anticipated Pain" in this study is a reflection of experienced pain or social learning. Both Anticipated Pain and DMFS show correlation to Dental Anxiety Scores in our correlation analysis, but only Anticipated Pain maintained a significant contribution in our multivariate analysis. Although dental treatment might be argued to inevitably involve some degree of discomfort or pain, our results indicate as others have shown that anxious patients expect more pain, and may also experience more pain (25). Thus, given the significance of adolescence in predicting future health behaviors (5), managing and reducing anxiety and stress related to dental treatment, as well as providing adequate pain relief and anesthetics, should be given high priority among dental professionals. The current study was not able to demonstrate a significant relationship between self-reported psychological distress and dental anxiety among adolescents, which might indicate that dental anxiety is more related to dental treatment experiences and expectations than more general psychological symptoms.

The caries experience in this study corresponds with findings from other counties in Norway and other Scandinavian countries (37). This study did not find that caries experience differed significantly between the anxious and non-anxious adolescents in the multivariate analysis. DMFS score correlated with both ratings of own oral health and control belief. The adolescents are good at judging own oral health related to caries disease (37). Our findings are interesting when viewed in contrast to findings from adult populations. For instance, even though Agdal (44) found that adult patients with dental 
phobia had worse oral health measures than non-phobic patients, they did find a "large variation in oral health and treatment needs” among these patients. The relationship between dental anxiety and caries thus appears associative rather than causal, and the association might be strengthened over time (for adult patients) as a function of for instance long-term avoidance and increasing treatment need.

Perception and attitude are important when it comes to oral health behavior (45). Adolescents scoring high on dental anxiety appear to have similar self-motivated attitudes and knowledge about oral health behavior as the ones scoring low on dental anxiety. Nevertheless, adolescents with high DAS scores viewed their own impact on oral health as low (control belief). Failing to believe that you can prevent caries has consequences for oral health behavior (45). Even though we could not demonstrate an impact on oral health at this stage, we could speculate that this belief does not promote a beneficial attitude to oral health over time.

Few studies have focused on embarrassment as an associative variable to dental anxiety. Moore (17) found embarrassment to be a complex phenomenon and qualitatively different among dentally anxious individuals, mostly present as a side-effect of dental anxiety and poor oral health status. We found that anxious adolescents reported significantly less embarrassment concerning caries than non-anxious. They reported being less motivated by recognition from others concerning oral health and oral health behavior. It is difficult to speculate about this finding, but it seems to signal that adolescents that are experiencing dental anxiety also are less prone to look for acceptance from others (parents, peers, etc.) for their oral health-related behaviors. This might perhaps imply some form of social disconnection (46), where a person distances themselves from the influence of others in order to come to terms with one's own feelings or escape scrutiny or criticism. This is particularly relevant when these feelings could be regarded as unusual or socially 
stigmatizing (47). This social disconnectedness could include avoiding the dental setting based on fear of evaluation and possible negative judgments from dental personnel.

In accordance with earlier findings in adults (48), there is a significant relationship between reporting missed dental appointments due to fear and DMFS among adolescents (37). This study indicates that avoidance is an important concept to dental anxiety among adolescents, as has been demonstrated among adults $(11,49)$. These findings imply that for adolescents the relation between dental status and dental anxiety is complex and has implications in the clinical setting. Early discovery and treatment of dental anxiety are essential to avoid a difference in dental status and an advanced treatment need, but in light of these results dental anxiety cannot be inferred by dental status alone, and early interventions targeting dental anxiety among adolescents will have to address the factors identified by this study. Evidence of high dental anxiety levels among adolescents without current or previous treatment need in their permanent dentition could reflect negative preconceptions in the adolescent population concerning dental treatment.

Since avoidance is problematic, preventive work concerning dental anxiety should expand beyond the clinical setting and could, for instance, include more collaboration with public health nurses. Overcoming the clinical challenges of dental anxiety in adolescents is often limited to reducing the physiological responses by medical sedation. Preventive strategies should target, not only oral disease but dental anxiety. It is essential to educate dental health professionals with regards to dental anxiety and to ensure that all dental health professional has the necessary skills to adapt to anxious patients, including enhanced communication skills. There are both qualitative and quantitative findings on the importance of establishing higher competence among dental professionals concerning this issue $(50,51)$. Also, there is a need to treat adolescents that already have established dental anxiety, and where preventive measures are not enough. There is evidence that a combination of cognitive behavioral techniques is more preferable in treating specific 
phobia in adults than general anesthesia (52). This treatment approach requires an established collaboration across disciplines and that could be one reason why the research literature on treatment of dental anxiety among adolescents is limited (3). However, there is evolving research in this field, especially related to a guided self-help cognitive behavioral approach (53) that could prove to be an effective treatment in this age group.

The public dental health care system in Norway provide free dental care to all children under the age of eighteen, thus, household economics may not be as important when considering dental attendance and dental treatment in this age group.

This study has the advantage of a large population base $(n=986)$ and a high attendance rate (92.2\%), providing a robust estimate on dental anxiety and associative relationships in the general adolescent population. Also, the study might be quite unique for adolescent populations in that it combines calibrated clinical examinations with questionnaires about behaviors and attitudes. There was a consensus between self-reported oral health status and caries findings in the clinical examination. To our knowledge, this kind of consensus has not been previously studied in this age group.

\section{Limitations}

A cross-sectional survey is limiting when trying to understand the different aspects of a complex problem like dental anxiety. Also, it is problematic in a study about dental anxiety to include a dental examination, which could lead to an underrepresentation of adolescents with dental anxiety that is not able to go through with this procedure. To our advantage, this study had a general health focus and the dental examination was only a small part of the study as a whole. All participants filled out the general questionnaire including dental anxiety score in a different location from where dental examination took place. Twenty-five adolescents that participated in the study did not attend the dental examination for unknown reasons. The study only included registered students, but we do not know how many adolescents did not attend school at this age, and what they potentially 
could contribute to our knowledge on this issue. However, upper secondary school is a statutory right in Norway (54) and registered students in the first year of this education should be representative of this age group since it includes adolescents that are not able to follow through with their studies.

The modern broad concept of oral health implies that more complex measures of oral health are needed. Any approach that seeks to describe oral health by discrete, underlying constituents could be argued to be somewhat artificial compared to how individuals experience their oral health. For instance, two individuals with the same DMFS score might vary considerably in their motivations and attitudes related to oral health. Therefore, we attempted to use variables that could tap into a broader definition of oral health related to motivation, attitudes and the social significance of tooth brushing. While similar items have been used earlier (38), the current study utilized a unique set of items that we felt required additional validation through exploratory factor analysis and reliability analyses. As part of this process we also decided to use a single item variable to measure control belief. This weakens the statistical evidence regarding this interesting concept. This study did not include questions about traumatic life events. Traumatic life events have a potentially negative effect on health and disease (55). With previous findings on how sexual abuse can affect dental anxiety and avoidance of dental treatment $(56,57)$, questions about traumatic life events, including abuse, should be considered in epidemiological studies on this issue. We also lack information about self-reported traumatic dental treatments. Teeth extractions in relation to orthodontic treatment, for example, could pose as a conditional event for dental anxiety in a caries free adolescent. Due to this lack of information we were not able to adjust for a theoretically important covariate in our multivariate analysis.

In conclusion, severe dental anxiety in adolescence is a dental public health challenge and this study shows that dental anxiety is a hindrance to seeking dental treatment 
irrespective of dental status. Dental anxiety should have a higher focus on preventive oral health strategies and have a higher priority on public dentistry to avoid this problem to escalate into adulthood. 


\section{Acknowledgments}

The authors would like to thank the study participants, the staff and dentists involved in the examination of participants at the university dental clinic in Tromsø, Fit Futures administration, and former Professor with the Department of Clinical Dentistry, UiT, Jan Bergdahl.

This study was funded by The Norwegian Directorate of Health, through Tromsø County Council. 


\section{References}

1. Klingberg G, Broberg AG. Dental fear/anxiety and dental behaviour management problems in children and adolescents: a review of prevalence and concomitant psychological factors. Int J Paediatr Dent. 2007;17(6):391-406.

2. Jaakkola S, Rautava P, Saarinen M, Lahti S, Mattila ML, Suominen S, et al. Dental fear and sense of coherence among 18-yr-old adolescents in Finland. Eur J Oral Sci. 2013;121(3pt2):247-51.

3. Seligman LD, Hovey JD, Chacon K, Ollendick TH. Dental anxiety: An understudied problem in youth. Clin Psychol Rev. 2017;55:25-40.

4. Blakemore S-J, Mills KL. Is adolescence a sensitive period for sociocultural processing? Annual Review of Psychology. 2014;65(1):187-207.

5. Sawyer SM, Afifi RA, Bearinger LH, Blakemore S-J, Dick B, Ezeh AC, et al. Adolescence: a foundation for future health. The Lancet. 2012;379(9826):1630-40.

6. Skaret E, Raadal M, Berg E, Kvale G. Dental anxiety and dental avoidance among 12 to 18 year olds in Norway. Eur J Oral Sci. 1999;107(6):422-8.

7. Locker D, Liddell A, Dempster L, Shapiro D. Age of onset of dental anxiety. J Dent Res. 1999;78(3):790-6.

8. Glick M, Williams DM, Kleinman DV, Vujicic M, Watt RG, Weyant RJ. A new definition for oral health developed by the FDI World Dental Federation opens the door to a universal definition of oral health. J Public Health Dent. 2017;77(1):3-5.

9. Eitner S, Wichmann M, Paulsen A, Holst S. Dental anxiety - an epidemiological study on its clinical correlation and effects on oral health. J Oral Rehabil. 2006;33(8):588-93.

10. Kruger E, Thomson WM, Poulton R, Davies S, Brown RH, Silva PA. Dental caries and changes in dental anxiety in late adolescence. Community Dent Oral Epidemiol. 1998;26(5):355-9.

11. Armfield JM, Stewart JF, Spencer AJ. The vicious cycle of dental fear: exploring the interplay between oral health, service utilization and dental fear. BMC Oral Health. 2007;7:1.

12. Armfield JM, Slade GD, Spencer AJ. Dental fear and adult oral health in Australia. Community Dent Oral Epidemiol. 2009;37(3):220-30.

13. Schuller AA, Willumsen T, Holst D. Are there differences in oral health and oral health behavior between individuals with high and low dental fear? Community Dent Oral Epidemiol. 2003;31(2):116-21.

14. Bell RA, Arcury TA, Anderson AM, Chen HY, Savoca MR, Gilbert GH, et al. Dental anxiety and oral health outcomes among rural older adults. J Public Health Dent. 2012;72(1):53-9.

15. DeDonno MA. Dental anxiety, dental visits and oral hygiene practices. Oral Health Prev Dent. 2012;10(2):129-33.

16. American Psychiatric Association. Diagnostic and statistical manual of mental disorders. Fourth edition ed. Association AP, editor. Washington, DC: American Psychiatric Association; 1994.

17. Moore R, Brødsgaard I, Rosenberg N. The contribution of embarrassment to phobic dental anxiety: a qualitative research study. BMC Psychiatry. 2004;4:10-1.

18. Vermaire JH, Houtem CMHH, Ross JN, Schuller AA. The burden of disease of dental anxiety: generic and disease-specific quality of life in patients with and without extreme levels of dental anxiety. Eur J Oral Sci. 2016. 
19. Mehrstedt M, John MT, Tönnies S, Micheelis W. Oral health-related quality of life in patients with dental anxiety. Community Dent Oral Epidemiol. 2007;35(5):35763.

20. Locker D. Psychosocial consequences of dental fear and anxiety. Community Dent Oral Epidemiol. 2003;31(2):144-51.

21. Bernson JM, Elfström ML, Hakeberg M. Dental coping strategies, general anxiety, and depression among adult patients with dental anxiety but with different dental-attendance patterns. Eur J Oral Sci. 2013;121(3pt2):270-6.

22. Stenebrand A, Boman UW, Hakeberg M. Dental anxiety and symptoms of general anxiety and depression in 15-year-olds. J Dent Hyg. 2013;11(2):99-104.

23. Henning Abrahamsson K, Berggren U, Carlsson SG. Psychosocial aspects of dental and general fears in dental phobic patients. Acta Odontol Scand. 2009;58(1):3743.

24. Maggirias J, Locker D. Psychological factors and perceptions of pain associated with dental treatment. Community Dent Oral Epidemiol. 2002;30(2):151-9.

25. Tickle M, Milsom K, Crawford FI, Aggarwal VR. Predictors of pain associated with routine procedures performed in general dental practice. Community Dent Oral Epidemiol. 2012;40(4):343-50.

26. Arntz A, van Eck M, Heijmans M. Predictions of dental pain: The fear of any expected evil, is worse than the evil itself. Behav Res Ther. 1990;28(1):29-41.

27. Kent G. Cognitive processes in dental anxiety. Br J Clin Psychol. 1985;24(4):259-64.

28. Brown DF, Moerenhout RG. The pain experience and psychological adjustment to orthodontic treatment of preadolescents, adolescents, and adults. American Journal of Orthodontics and Dentofacial Orthopedics. 1991;100(4):349-56.

29. Sandhu SS, Sandhu J. Orthodontic pain: an interaction between age and sex in early and middle adolescence. The Angle Orthodontist. 2013;83(6):966-72.

30. McLean CP, Anderson ER. Brave men and timid women? A review of the gender differences in fear and anxiety. Clin Psychol Rev. 2009;29(6):496-505.

31. Corah NL. Development of a dental anxiety scale. J Dent Res. 1969;48.

32. Locker D, Poulton R, Thomson WM. Psychological disorders and dental anxiety in a young adult population. Community Dent Oral Epidemiol. 2001;29(6):456-63.

33. Thomson WM, Poulton RG, Kruger E, Davies S, Brown RH, Silva PA. Changes in self-reported dental anxiety in new zealand adolescents from ages 15 to 18 years. J Dent Res. 1997;76 (6).

34. Corah NL, Gale EN, Illig SJ. Assessment of a dental anxiety scale. J Am Dent Assoc. 1978;97.

35. Larmas M. Has dental caries prevalence some connection with caries index values in adults? Caries Res. 2010;44(1):81-4.

36. Broadbent JM, Thomson WM. For debate: problems with the DMF index pertinent to dental caries data analysis. Community Dent Oral Epidemiol. 2005;33(6):400-9.

37. Jacobsen ID, Eriksen HM, Espelid I, Schmalfuss A, Ullbro C, Crossner CG. Prevalence of dental caries among 16-year-olds in Troms County, Northern Norway. Swed Dent J. 2016;40(2):191-201.

38. Tolvanen M, Lahti S, Hausen $\mathrm{H}$. Changes in toothbrushing frequency in relation to changes in oral health-related knowledge and attitudes among children $-\mathrm{a}$ longitudinal study. Eur J Oral Sci. 2010;118(3):284-9. 
39. Tolvanen M, Lahti S, Miettunen J, Hausen H. Relationship between oral healthrelated knowledge, attitudes and behavior among 15-16-year-old adolescents-A structural equation modeling approach. Acta Odontol Scand. 2012;70(2):169-76. 40. Haavet OR, Sirpal MK, Haugen W, Christensen KS. Diagnosis of depressed young people in primary health care-a validation of HSCL-10. Family Practice. 2011;28(2):233-7.

41. Strand BH, Dalgard OS, Tambs K, Rognerud M. Measuring the mental health status of the Norwegian population: A comparison of the instruments SCL-25, SCL-10, SCL-5 and MHI-5 (SF-36). Nord J Psychiatry. 2003;57(2):113.

42. Locker D, Thomson WM, Poulton R. Psychological disorder, conditioning experiences, and the onset of dental anxiety in early adulthood. J Dent Res. 2001;80(6):1588-92.

43. Shim Y-S, Kim A-H, Jeon E-Y, An S-Y. Dental fear \& anxiety and dental pain in children and adolescents; a systemic review. J Dent Anesth Pain Med. 2015;15(2):5361.

44. Agdal LM, Raadal M, Skaret E, Kvale G. Oral health and oral treatment needs in patients fulfilling the DSM-IV criteria for dental phobia: Possible influence on the outcome of cognitive behavioral therapy. Acta Odontol Scand. 2008;66(1):1-6.

45. Ericsson JS, Östberg AL, Wennström JL, Abrahamsson KH. Oral health-related perceptions, attitudes, and behavior in relation to oral hygiene conditions in an adolescent population. Eur J Oral Sci. 2012;120(4):335-41.

46. Hall-Lande J, Eisenberg ME, Christenson SL, Neumark-Sztainer D. Social isolation, psychological health, and protective factors in adolescence. Adolescence. 2007;42(166): 265-86.

47. Strauss RS, Pollack HA. Social marginalization of overweight children. Archives of Pediatrics \& Adolescent Medicine. 2003;157(8):746-52.

48. Armfield JM. What goes around comes around: revisiting the hypothesized vicious cycle of dental fear and avoidance. Community Dent Oral Epidemiol. 2013;41(3):279-87.

49. De Jongh A, Schutjes M, Aartman IH. A test of Berggren's model of dental fear and anxiety. Eur J Oral Sci. 2011;119(5):361-5.

50. Morgan AG, Rodd HD, Porritt JM, Baker SR, Creswell C, Newton T, et al. Children's experiences of dental anxiety. Int J Paediatr Dent. 2017;27(2):87-97.

51. Jaakkola S, Lahti S, Räihä H, Saarinen M, Tolvanen M, Aromaa M, et al. Dental fear affects adolescent perception of interaction with dental staff. Eur J Oral Sci. 2014;122(5):339-45.

52. Wide Boman U, Carlsson V, Westin M, Hakeberg M. Psychological treatment of dental anxiety among adults: a systematic review. Eur J Oral Sci. 2013;121(3 Pt

2):225-34.

53. Porritt J, Rodd H, Morgan A, Williams C, Gupta E, Kirby J, et al. Development and Testing of a Cognitive Behavioral Therapy Resource for Children's Dental Anxiety. JDR Clinical \& Translational Research. 2017;2(1):23-37.

54. Lov om grunnskolen og den vidaregåande opplæringa (opplæringslova), (LOV2017-06-16-63 fra 01.01.2018).

55. Bureau J-F, Martin J, Lyons-Ruth K, van der Kolk BA, d'Andrea W, Ford JD, et al. The Impact of Early Life Trauma on Health and Disease: The Hidden Epidemic United States of America, New York: Cambridge University Press; 2010.

56. Humphris G, King K. The prevalence of dental anxiety across previous distressing experiences. J Anxiety Disord. 2011;25(2):232-6. 
57. Willumsen T. Dental fear in sexually abused women. Eur J Oral Sci. 2001;109(5):291-6. 


\section{Figure legends:}

Figure 1. Concepts of interest when exploring possible associations with dental anxiety scores

Figure 2. Flow chart, participation in Fit Future 1, Tromsø study, 2010/2011

Figure 3. The independent variables in our logistic regression model, arrows indicating a significant association with dental anxiety 
Table 1. Rotated two-component factor solution for questionnaire items, percentage of common variance explained, and factor loading.

Knowledge and attitudes about tooth brushing

(Self-motivation) (27.7\%)

15. Brushing teeth is very important for me to have fresh breath 749

14. Brushing teeth is very important for me to avoid tooth discoloration $\quad$.738

8. Brushing teeth is very important for me when going to school $\quad$ 725

13. Brushing teeth is very important for me to avoid caries 692

16. Brushing teeth is very important for me to have healthy gingiva 691

7. Brushing teeth is very important for me when going to meet my girlfriend $\quad$.661 / boyfriend

6. Brushing teeth is very important for me when going to meet friends (disco $\quad .654$ etc.)

9. Brushing teeth is very important for me when going to meet my best friend $\quad$ 645

17. Brushing teeth is very important for me to look better 635

12. Brushing teeth is very important for me to feel healthy 604

4. You should brush your teeth twice daily $\quad .574$

10. Brushing teeth is very important for me when participating in sports / $\quad .559$ hobbies

11. Brushing teeth is very important for me when going to the dentist 524

5. You can prevent dental caries by using fluoridated toothpaste $\quad .451$

3. I can prevent caries by daily tooth brushing $\quad 357$

2. My parents don't care if I develop caries -,307

Embarrassment of having caries and recognition from parents and friends (Social motivation) (15.3\%)

20. It would have been embarrassing for me if my father got caries in his teeth

19. It would have been embarrassing for me if my mother got caries in her teeth

21. It would have been embarrassing for me if my friend got caries in his/her

22. Brushing teeth is very important for me to be recognized by my parents

23. Brushing teeth is very important for me to be recognized by my friends

18. It would have been embarrassing for me if I got caries in my teeth

\section{Single item}

1. Whatever I do, it doesn't help to prevent caries 
Table 2. Demographics

\begin{tabular}{|c|c|c|}
\hline Variable & $N$ & Percentage \\
\hline Age & 986 & \\
\hline 15 & 52 & 5.3 \\
\hline 16 & 770 & 78.1 \\
\hline 17 & 139 & 14.1 \\
\hline 18 & 25 & 2.5 \\
\hline Sex & $N$ & Percentage \\
\hline Females & 509 & 51.6 \\
\hline Males & 477 & 48.4 \\
\hline Birthplace & & \\
\hline Total & 974 & 100 \\
\hline Norway & 924 & 94.9 \\
\hline Other & 50 & 5.1 \\
\hline $\begin{array}{l}\text { Parents } \\
\text { education }\end{array}$ & $N$ & Don't know \\
\hline Mother & 967 & $26.2 \%$ \\
\hline Father & 951 & $29.2 \%$ \\
\hline Birthplace & $N$ & Norway \\
\hline Mother & 974 & $91.5 \%$ \\
\hline Father & 974 & $91.0 \%$ \\
\hline
\end{tabular}


Table 3. Descriptive statistics

\begin{tabular}{|c|c|c|c|c|}
\hline $\begin{array}{l}\text { Dental anxiety } \\
\text { score }\end{array}$ & $N$ & Mean & Median & $S D$ \\
\hline DAS sum & 951 & 8.0 & 7.0 & 3.5 \\
\hline Male & 487 & 7.3 & 6.0 & 3.1 \\
\hline Female & $\begin{array}{c}464 \\
N\end{array}$ & $\begin{array}{c}8.7 \\
\text { Percentaae }\end{array}$ & $\begin{array}{c}8.0 \\
\text { Female (\%) }\end{array}$ & $\begin{array}{c}3.6 \\
\text { Male (\%) }\end{array}$ \\
\hline$D A S \leq 12$ & 872 & 88.4 & $401(84.1)$ & 471 (92.5) \\
\hline$D A S \geq 13$ & 114 & 11.6 & 76 (15.9) & 38 (7.5) \\
\hline
\end{tabular}

$\begin{array}{rcccc}\begin{array}{l}\text { Mental health } \\ \text { symptoms }\end{array} & N & \text { Mean } & \text { Median } & S D \\ \text { HSCL-10 } & 952 & 1.49 & 1.30 & .53 \\ \text { Male } & 487 & 1.36 & 1.20 & .42 \\ \text { Female } & 465 & 1.63 & 1.40 & .60 \\ \text { HSCL-10 } \leq 1.84 & N & \% & \text { Females (\%) } & \text { Males (\%) } \\ \text { HSCL-10 } 1.85 & 181 & 81 & 339(72.9) & 432(88.7) \\ \end{array}$

\begin{tabular}{lccccc} 
Oral Health & & $N$ & Mean & Median & $S D$ \\
DMFT & & 961 & 4.35 & 4.00 & 3.85 \\
& Male & 494 & 4.17 & 3.00 & 3.86 \\
\multirow{2}{*}{ DMFS } & Female & 497 & 4.55 & 4.00 & 3.85 \\
& & 961 & 6.39 & 4.00 & 6.99 \\
& Male & 494 & 6.17 & 4.00 & 7.19 \\
& Female & 497 & 6.63 & 5.00 & 6.76
\end{tabular}

\section{Expected pain at}

the dentist and

Mean Median SD

avoidance

$\begin{array}{rcccc}\text { Pain } & 964 & 3.05 & 2.00 & 2.76 \\ & & \text { Yes }(\%) & \text { No }(\%) & \text { SD } \\ \text { Avoidance } & 958 & 72(7.5) & 886(92.5) & .264\end{array}$

$\begin{array}{rcccc}\begin{array}{l}\text { Concerning oral } \\ \text { health behavior }\end{array} & N & \text { Mean } & \text { Median } & S D \\ \text { Self-motivation } & 903 & 25.42 & 25.00 & 6.26 \\ \text { Social motivation } & 945 & 18.66 & 18.00 & 3.52 \\ & N & \begin{array}{c}\text { Low self- } \\ \text { control }\end{array} & \text { High self-control } & S D \\ \text { Control belief } & 959 & 126 & 833 & 34\end{array}$


Table 4. Correlation table

\begin{tabular}{|c|c|c|c|c|c|c|c|c|c|c|c|c|}
\hline & 1 & 2 & 3 & 4 & 5 & 6 & 7 & 8 & 9 & 10 & 11 & 12 \\
\hline \multicolumn{13}{|l|}{ 1.Sum DAS score } \\
\hline $\begin{array}{l}\text { 2. Average HSCL-10 } \\
\text { score }\end{array}$ & $.219^{* *}$ & & & & & & & & & & & \\
\hline 3. Sex & $-.214^{* *}$ & -.261 & & & & & & & & & & \\
\hline 4. Pain at dentist & $.731^{* *}$ & $.157^{* *}$ & $-.075^{*}$ & & & & & & & & & \\
\hline $\begin{array}{l}\text { 5. Avoid smiling due } \\
\text { to appearance }\end{array}$ & $.137^{* *}$ & $.258^{* *}$ & -.056 & $.166^{* *}$ & & & & & & & & \\
\hline $\begin{array}{l}\text { 6. Missed dental } \\
\text { appointments }\end{array}$ & $.395^{* *}$ & $.137^{* *}$ & -.039 & $.362^{* *}$ & $.075^{*}$ & & & & & & & \\
\hline 7. DMFS & $.261^{* *}$ & $.069^{*}$ & -.033 & $.299^{* *}$ & $.081^{*}$ & $.212^{* *}$ & & & & & & \\
\hline $\begin{array}{l}\text { 8. Embarrassment } \\
\text { and recognition } \\
\text { score }\end{array}$ & -.022 & $.070^{*}$ & $-.064^{*}$ & -.059 & $-.082^{*}$ & $-.069^{*}$ & .019 & & & & & \\
\hline $\begin{array}{l}\text { 9. Knowledge and } \\
\text { attitudes concerning } \\
\text { tooth brushing }\end{array}$ & -.061 & $.076^{*}$ & $.255^{* *}$ & .002 & .003 & -.042 & -.041 & $.222^{* *}$ & & & & \\
\hline $\begin{array}{l}\text { 10. How do you rate } \\
\text { own oral health }\end{array}$ & $.222^{* *}$ & $.188^{* *}$ & $.130^{* *}$ & $.248^{* *}$ & $.244^{* *}$ & $.119^{* *}$ & $.319^{* *}$ & $.091^{* *}$ & $.224^{* *}$ & & & \\
\hline 11. Control belief & $-.248^{* *}$ & -.063 & -.019 & $-.285^{* *}$ & -.062 & $-.133^{* *}$ & $-.312^{* *}$ & $.081^{*}$ & $-.150^{* *}$ & $-.304^{* *}$ & & \\
\hline $\begin{array}{l}\text { 12. How often do } \\
\text { you brush your teeth }\end{array}$ & -.034 & $-.068^{*}$ & $-.300^{* *}$ & $-.084^{* *}$ & $-.072 *$ & $-.103^{* *}$ & $-.174^{* *}$ & .007 & $-.315^{* *}$ & $-.394^{* *}$ & $.140^{* *}$ & \\
\hline
\end{tabular}


Table 5. Logistic regression model for DAS score $\geq 13$

\begin{tabular}{|c|c|c|c|c|c|c|c|c|}
\hline Variables & B & S.E & Wald & $D f$ & $\boldsymbol{P}$ & $\begin{array}{l}\text { Odds } \\
\text { Ratio }\end{array}$ & \multicolumn{2}{|c|}{$\begin{array}{c}95 \% \text { CI for } \\
\text { OR } \\
\text { Lower Upper }\end{array}$} \\
\hline Sex & .76 & .33 & 5.71 & 1 & .017 & 2.19 & 1.15 & 4.17 \\
\hline HSCL-10 & .41 & .25 & 2.77 & 1 & .096 & 1.50 & .93 & 2.43 \\
\hline DMFS & -.02 & .02 & .44 & 1 & .507 & .99 & .94 & 1.03 \\
\hline Pain & .68 & .07 & 102.83 & 1 & .000 & 1.98 & 1.74 & 2.27 \\
\hline Avoidance & 1.24 & .43 & 8.40 & 1 & .004 & 3.44 & 1.49 & 7.93 \\
\hline $\begin{array}{c}\text { Self- } \\
\text { motivation }\end{array}$ & .50 & .32 & 2.47 & 1 & .116 & 1.64 & .88 & 3.05 \\
\hline $\begin{array}{c}\text { Social } \\
\text { motivation }\end{array}$ & -.76 & .32 & 5.57 & 1 & .018 & .47 & .25 & .88 \\
\hline $\begin{array}{c}\text { Control } \\
\text { belief }\end{array}$ & 1.46 & .38 & 15.13 & 1 & .000 & 4.33 & 2.07 & 9.05 \\
\hline Constant & -6.73 & .67 & 101.86 & 1 & .000 & .00 & & \\
\hline $\begin{array}{l}\chi^{2} \\
D f\end{array}$ & & & & & & & & \\
\hline
\end{tabular}

